at strong depolarizations, inactivation is largely complete within $-100 \mathrm{~ms}$ (Fig. $3 \mathrm{a}$, bottom family of traces). A steady holding potential of $-20 \mathrm{mV}$ also produces complete inactivation (Fig. $3 a$, middle trace); $50 \%$ inactivation is seen at h.p. $=-60 \mathrm{mV}$ (trace not shown). As Fig. $3 b$ illustrates, the open probability $(p)$ increases over the range between -20 and $+30 \mathrm{mV}$, in good agreement with recordings from whole cells (Fig. 1c) and patches with only one or a few N-type channels (Fig. $2 b$ ).

In addition to differences in kinetics, unitary conductance and sensitivity to $\mathrm{Cd}$, we find that the three channel types differ in their responsiveness to Bay $\mathrm{K} 8644$. This dihydropyridine $\mathrm{Ca}$ agonist $^{23}$ elevates calcium influx by promoting a pattern of $\mathrm{Ca}$ channel gating with very long openings in neurones ${ }^{24}$ and heart cells $^{25-28}$. Bay $\mathbb{K} 8644$ strongly enhances averaged L-type channel currents in DRG neurones ${ }^{1,24}$ (Fig. 4), but produces no change in the current carried by T-type channels ( 6 patches) or N-type channels (4 patches). Our results with Bay K 8644 are consistent with findings of dihydropyridine-resistant Ca channels in GH3 cells ${ }^{18}$ and cardiac cells ${ }^{29}$. The existence of different dihydropyridine-resistant channels in neurones might help explain the partial or complete lack of effect of dihydropyridines on depolarization-induced $\mathrm{Ca}$ entry or transmitter release in many systems ${ }^{30,31}$.

Although this is the first report to focus on the coexistence of three types of calcium channels in one preparation, we believe that activity of all three channel types may be found in whole-cell currents reported by others (for example Fig. $1 c$ of ref. 8). Single-channel recordings in DRG neurones by Carbone and Lux ${ }^{9}$ have shown two types of unitary activity that correspond kinetically to what we call T-type and L-type Ca channels. The relative sizes of the unitary currents with $40 \mathrm{mM} \mathrm{Ca}$ as the charge carrier are opposite to what we find with $110 \mathrm{mM} \mathrm{Ba}$; this discrepancy might be explained by the very different ionic selectivity properties of $\mathrm{T}$ - and L-type Ca channels ${ }^{10,17,29}$.

It is attractive to suppose that the various channels may serve different cellular functions. For example, T-type channels might contribute to threshold behaviour or rhythmic activity and $\mathrm{N}$ or L-type channels may be important for dendritic spikes or neurotransmitter release ${ }^{3-5,11,17}$. Determination of the cellular distribution of the channel types and their sensitivity to neuromodulators will help in the elucidation of their physiological roles.

We thank So-Ching Wong for preparing the cultured neurones and for help with the illustrations, and E. W. McCleskey, P. Hess, B. Nilius and J. B. Lansman for helpful discussion. Support was provided by a Canadian Heart Foundation Fellowship to A.P.F. and USPHS grants to M.C.N. \& R.W.T.

Received 7 February; accepted 22 May 1985.

Miller, R. J. Trends Neurosci, 8, 45-47 (1985

2. Hagiwara, S. \& Byerly, L. Trends Neurosci. 6, 189-193 (1983

3. Llinas, R., Steinberg, I. Z. \& Watton, K. Biophys. J. 33, 323-352 (1981)

Fishman, M. C. \& Spector, I. Proc. main. Acad. Sci. U.S.A. 78, 5245-5249 (1981)

Llinas, R. \& Sugimori, M. J. Physiol, Lond. 305, 197-213 (1980)

Murase K. \& Randic, M. J. Physiol, Lond. 344, 141-153 (1983)

Nowycky, M. C. Fox, A. P. \& Tsien, R. W. Biophys. J. 45, 36a (1984).

Nowycky, M. C., Fox, A. P. \& Tsien, R. W. Biophys. J. 45,
Carbone, E. \& Lux, H. D. Biophys. J. 46, $413 \times 418$ (1984)

Carbone, E. \& Lux, H. D. Nature 310, 501-502 (1984).

Yoshii, M., Tsunoo, A. \& Narahashi, T. Biophys. J. 47, 433a (1984).

11. Brown, D. A. et al. IUPHAR Proc. (in the press).

12. Fedulova, S. A., Kostyuk, P. G. \& Veselovsky, N. S. J. Physiol, Lond. 359, 431-446 (1985)

13. Bossu, J.-L., Feltz, A. \& Thomann, J.-M. Pflügers Arch. ges. Physiol. (in the press).

14. Hagiwara, S., Ozawa, S. \& Sand, O. I. gen Physiol. 65, 617-644 (1975).

5eitmer, J. W. J. Physiol, Lond 353, 137-159(1984).

Fox, A. P. \& Krisne, S. J. Physiol, Lond. 356, 491-505 (1984

. Armstrong, C. M. \& Matteson, D. R. Science 227, 65-67 (1985)

8. Cohen, C. J. \& McCarthy, R. T. Biophys. J. 47, 513 a (1985)

19. Curtis, B. M. \& Catterall, W. A. J. biol. Chem. 258, 9344-9348 (1983).

20. Norman, R. I., Borsotto, M., Fosset, M. \& Lazdunski, M. Biochem. biophys. Res. Commun. III, $878-883$ (1983)

21. Glossman, H., Ferry, D. R., Lubbecke, F., Mewes, R. \& Hofiman, F. Trends pharmac. Sci $3,43)-437(1982)$

Nowycky, M. C., Fox, A. P. \& Tsien, R. W. Soc. Neurosci. Abstr. 10, 526 (1984)

Schramm, M., Thomas, G., Towart, R. \& Franckowiak, G. Nature 303, 535-537 (1983).

Nowycky, M. C. Fox, A. P. \& Tsien, R. W. Proc natn. Acad. Sci. U. S. A. 82, $2178-2182(1985)$

Kokubun, S. \& Reuter, H. Proc natm. Acad Sci. U.S.A. 81, 4824-4827 (1984).

Ochi, R., Hino, N. \& Nimi, Y. Proc. Jap. Acad. B60, 153-156 (1984).

Hess, P. Lansman, J. B. \& Tsien, R. W. Narure 311, 538-544 (1984)

Brown, A. M., Kunze, D. L. \& Yatani, A. Nature 31i, 570-572(1984).

\section{A novel type of cardiac calcium channel in ventricular cells}

\section{B. Nilius}

Julius Bernstein Institute of Physiology, Martin Luther Universität, 4020 Halle (Saale), GDR

\section{P. Hess, J. B. Lansman* \& R. W. Tsien ${ }^{*}$}

Department of Physiology, Yale University School of Medicine, New Haven, Connecticut 06510, USA

Calcium influx is vital for several aspects of cardiac activity, so it is important to ask if heart cells possess a single or multiple types of $\mathrm{Ca}$ channel. Only one Ca channel type has been identified in patch-clamp studies of unitary current $t^{-3}$, despite suggestions to the contrary from whole-cell recordings in heart cells ${ }^{4-6}$ and unitary recordings from other cells ${ }^{7,8}$. Here we describe a novel type of cardiac Ca channel with several properties that distinguish it from the hitherto-identified Ca channel in heart cells. Its conductance in isotonic $\mathbf{B a}$ is small $(8 \mathrm{pS})$, and is no larger in $\mathrm{Ba}$ than in Ca. It activates and inactivates at relatively megative potentials and remains functional long after patch excision. It is insensitive to dihydropyridines such as nimodipine and the $\mathrm{Ca}$ agonist Bay $K \mathbf{~ 8 6 4 4}$, and is more resistant to block by external Cd than the previously described type of cardiac Ca channel.

Figure 1 illustrates some of the features that distinguish the two types of $\mathrm{Ca}$ channel. Activity of the previously described type of cardiac Ca channel (Fig. 1 a) was evoked by depolarizing voltage-clamp pulses to $+10 \mathrm{mV}$ from a holding potential of $-50 \mathrm{mV}$; with $110 \mathrm{mM} \mathrm{Ba}$ in the pipette, channel openings produce current pulses of $\sim 1.2 \mathrm{pA}$ amplitude. The pattern of activity is typified by brief openings occurring in clusters throughout the pulse, with occasional sweeps dominated by long-lasting openings. The averaged current is fairly wellmaintained. Figure $1 b$ shows strikingly different channel activity, recorded from the same patch with pulses from a holding potential of $-70 \mathrm{mV}$ to $-20 \mathrm{mV}$, a test potential that is normally too negative with $110 \mathrm{mM} \mathrm{Ba}$ in the pipette to activate the hithertoidentified channel. Here openings appear as inward current pulses of $\sim 0.5 \mathrm{pA}$ amplitude, and are generally grouped as one burst of activity that tends to occur near the beginning of each pulse; the averaged current peaks at $\sim 10 \mathrm{~ms}$ and then decays rapidly. As the unitary current is larger in Fig. $1 a$ than in $b$, despite the smaller driving force for Ba entry at the more positive test potential, there can be little doubt of the existence of two different kinds of channel. The slope conductance between -50 and $0 \mathrm{mV}$ is $8 \mathrm{pS}$ for the channel type in Fig. $1 b$, considerably smaller than the conductance of the type in a $(18-25 \mathrm{pS}$ in $\sim 100 \mathrm{mM} \mathrm{Ba}$, from our own studies and refs 1,2). The two channels also differ in their ability to conduct $\mathrm{Ca}$ or Ba. Unlike the previously described $\mathrm{Ca}$ channel, which supports a much larger unitary flux with $\mathrm{Ba}$ than with $\mathrm{Ca}$ (compare Figs $1 a$ and $3 c, d)$, the second type of Ca channel shows very similar singlechannel currents with either ion (Fig. 1b,c). The time course of the averaged currents is also very much the same.

As suggested by the voltage protocols in Fig. 1, we found major differences in the voltage-dependence of the two channel types. With $110 \mathrm{mM} \mathrm{Ba}$ in the pipette, the second type of $\mathrm{Ca}$ channel showed detectable activation and $90 \%$ complete steadystate inactivation near $-50 \mathrm{mV}$, about $40 \mathrm{mV}$ negative to a corresponding potential for the previously described type of $\mathrm{Ca}$ channel.

Although the voltage dependence of the new type of channel qualitatively resembles that of $\mathrm{Na}$ channels, the unitary events cannot be explained by $\mathrm{Ca}$ or $\mathrm{Ba}$ movements through $\mathrm{Na}$ channels: they persist in the presence of doses of tetrodotoxin (TTX, 


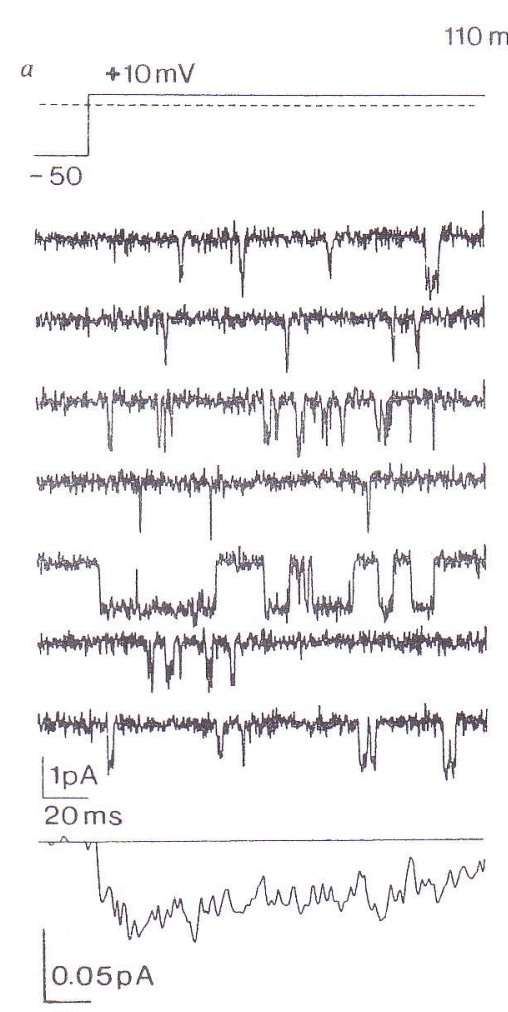

$110 \mathrm{mMBa}$
LETIERSTONATURE

$110 \mathrm{mMCa}$

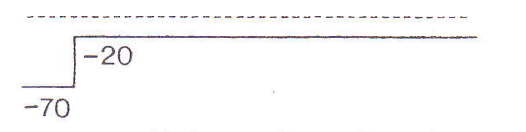

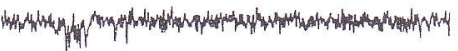

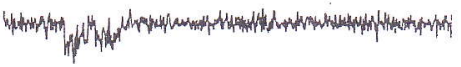

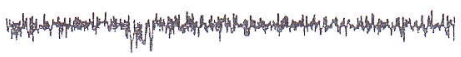

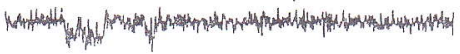

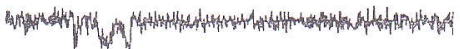

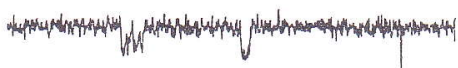

19.

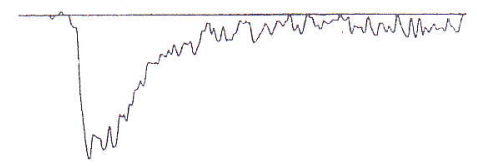

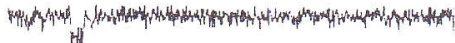

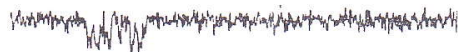

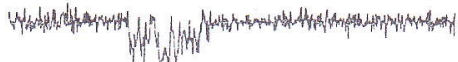

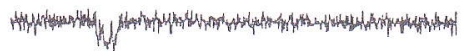

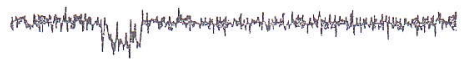

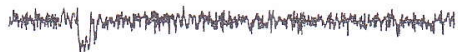

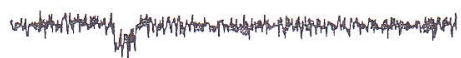

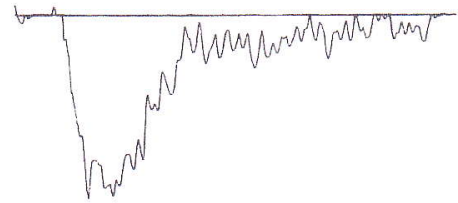

Fig. 1 Evidence for the coexistence of two distinct types of $\mathrm{Ca}$ channel in guinea pig ventricular cells. $a, b$, Cell-attached patch recordings with $110 \mathrm{mM} \mathrm{Ba}$ in the pipette. Activity of previously described type of Ca channel $(a)$ or novel type of Ca channel $(b)$ was evoked by appropriate voltage clamp protocols (top row). Zero membrane potential is indicated by the dotted line. A voltage step from a holding potential of $-70 \mathrm{mV}$ to a test potential of $+10 \mathrm{mV}$ produced a mixture of both types of activity (traces not shown). Selected sweeps with clearly detectable channel activity are illustrated. Averaged currents (bottom row) were obtained from all sweeps in each run (294 sweeps in $a, 270$ sweeps in b). The amplitude of the averaged currents is not meant to represent the overall balance between the two types of activity. Cell B2E. $c$, Current traces recorded with $110 \mathrm{mM} \mathrm{Ca}$ in the pipette with the same voltage protocol as in $b$. The average current (bottom) was obtained from 179 sweeps. Note that the unitary current amplitude and average current time course are very similar with either $110 \mathrm{mM} \mathrm{Ca}$ or $110 \mathrm{mM} \mathrm{Ba}$ as the charge carrier. Cell B2C.

Methods. Single guinea pig ventricular myocytes were freshly dissociated by enzymatic dispersion ${ }^{22}$. Cell-attached patch-clamp recordings ${ }^{23}$ were made at room temperature $\left(21^{\circ} \mathrm{C}\right)$ with depolarizing pulses applied every $3 \mathrm{~s}$. Patch pipettes contained $110 \mathrm{mM} \mathrm{BaCl}_{2}$ or $\mathrm{CaCl}_{2}$ plus $10 \mathrm{mM}$ HEPES ( $p \mathrm{H} 7.5$ with tetraethylammonium-OH). The membrane potential outside the patch was zeroed by an external solution containing (in $\mathrm{mM}$ ): K-aspartate 140, EGTA 10, HEPES 10 (titrated to $\mathrm{pH} 7.5$ with $\mathrm{KOH}$ ). The current traces were filtered $(-3 \mathrm{db}$ at $1 \mathrm{kHz}, 8$-pole Bessel filter), digitized at $5 \mathrm{kHz}$, stored and analysed on a laboratory computer. Capacity and leak currents were subtracted digitally.

$a$

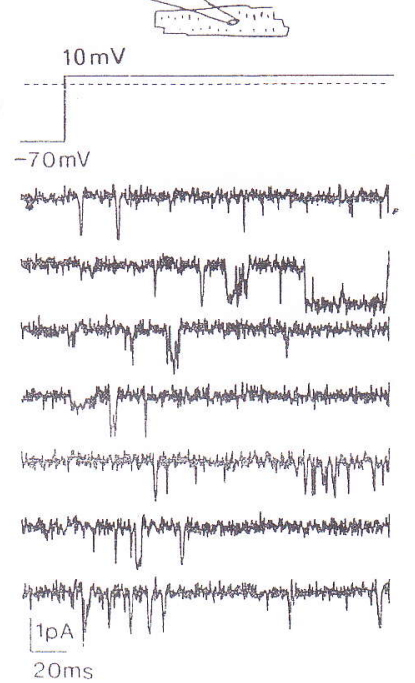

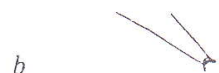

$10 \mathrm{mV}$

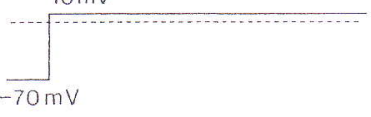

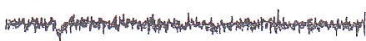

Why

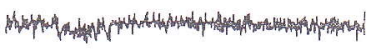

mathend

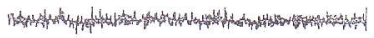

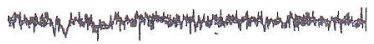

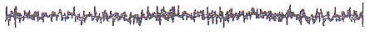

$c$

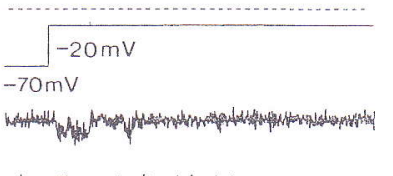

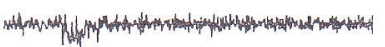

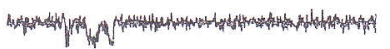

1)

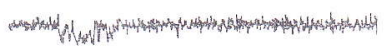

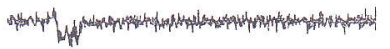

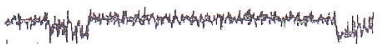

$1 \mathrm{pA}$

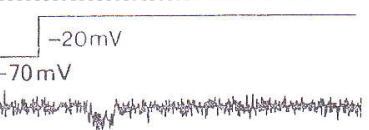

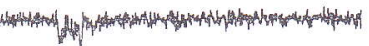

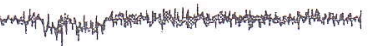

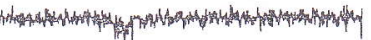

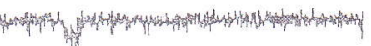

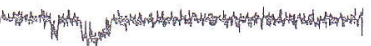

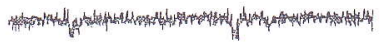

Fig. 2 Differential effect of patch excision on the two types of Ca channels in a single patch. $a, c$, Cell-attached patch recordings of combined L-type and T-type $\mathrm{Ca}$ channel activity $10 \mathrm{~min}$ before excision $(a)$ and exclusively $\mathrm{T}$-type Ca channel activity $6 \mathrm{~min}$ before excision ( $c$ ). $b, d$, 


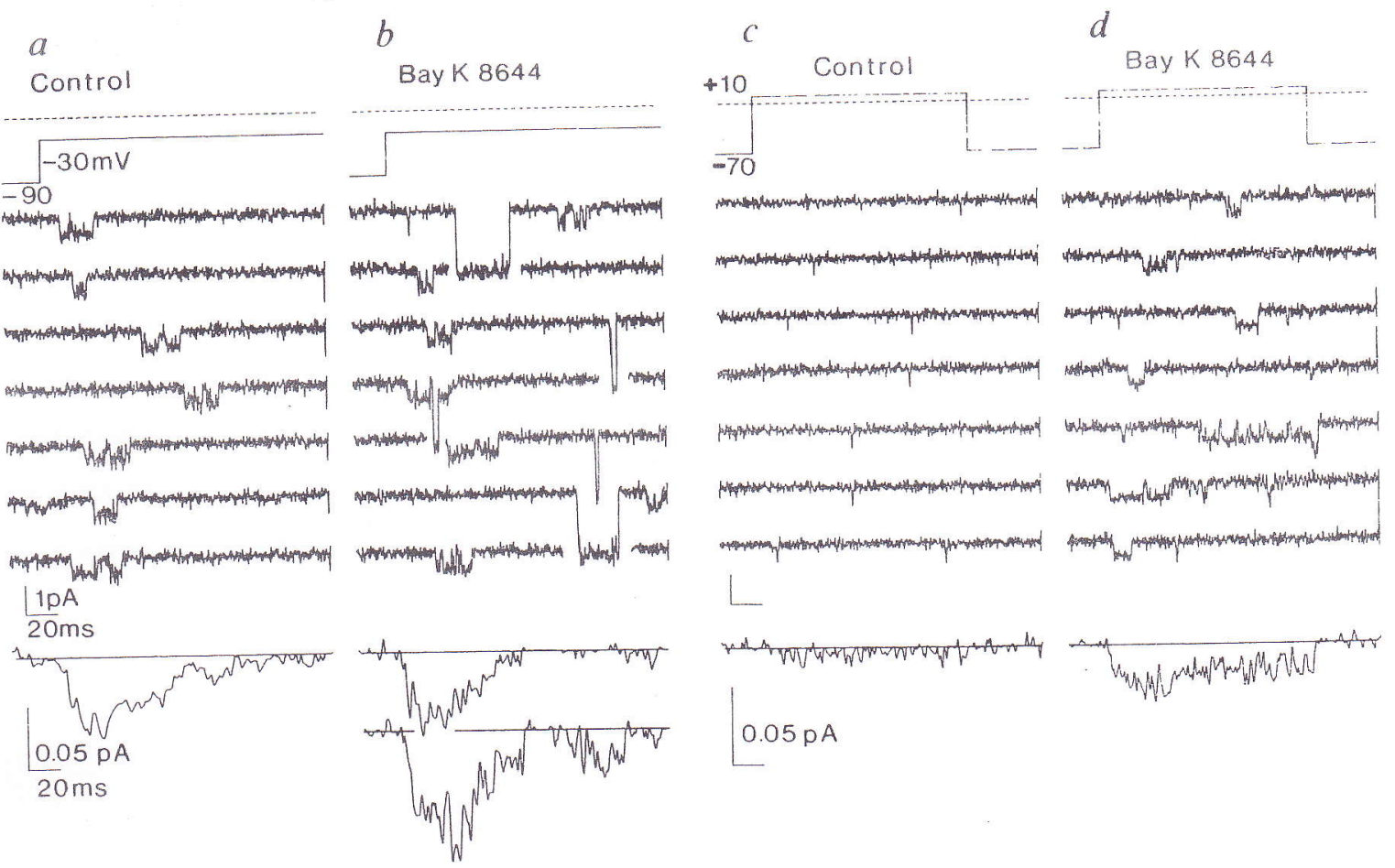

Fig. 3 Differential effect of the dihydropyridine Ca channel agonist Bay K 8644 on the two channel types with Ba or Ca as the charge carrier. Fig. 3 Differential effect of the dihydropyridine Ca channel agonist Bay $\mathrm{K} 8644$ on the two channel types with $\mathrm{Ba}$ or $\mathrm{Ca}$ as the changere $(a)$ and after (b) exposure of the cell to $5 \mu \mathrm{M}$ Bay K 8644. Sweeps with no detectable openings not shown. Lowest traces in each column are averaged currents from all sweeps ( 234 in $a, 274$ in $b$ ). Column $b$ also includes a smaller average current signal (just above lowest trace), obtained from 194 selected sweeps that showed no detectable activity of the large conductance channel. Cell B3D. $c, d, 110 \mathrm{mM} \mathrm{Ca}$ in the pipette. Current traces from a patch with only L-type Ca channel activity before $(c)$ and after $(d)$ exposure of the cell to $5 \mu \mathrm{M}$ Bay K 8644 . Sweeps with no detectable openings not shown. Mean currents (below individual traces) are averages of $151(c)$ and $518(d)$ sweeps. Cell B7E.

$33 \mu \mathrm{M}$; see Fig. 3) or lidocaine $(0.5 \mathrm{mM})$ known to abolish $\mathrm{Na}$ channel current; they are about 50 times larger than predicted from estimates of the permeability ratio $\mathrm{P}_{\mathrm{Ca}} / \mathrm{P}_{\mathrm{Na}}$ for the $\mathrm{Na}$ channel $^{9}$ and measurements of unitary Na currents ${ }^{10,11}$. Furthermore, when studied with pipettes of comparable dimensions $(\sim 2-2.5 \mu \mathrm{m}$ diameter $)$, the number of functional $\mathrm{Na}$ channels with $130 \mathrm{mMN} \mathrm{Na}$ as charge carrier is typically greater than 10 per patch, while the number of the new type of $\mathrm{Ca}$ channels with $110 \mathrm{mM} \mathrm{Ba}$ or $\mathrm{Ca}$ ranged from 0 to at most 3. The $\mathrm{Ca}$ channel activity in Fig. $1 b, c$ can be labelled ' $T$ ' for its markedly transient time course, very much like the T-type $\mathrm{Ca}$ channel in dorsal root ganglion (DRG) neurones; ${ }^{8}$ by way of contrast, the previously described type of cardiac Ca channel (Fig. 1a) is large in unitary conductance (with $\mathrm{Ba}$ as the charge carrier) and long-lasting in time course, and will be referred to as ' $L$ '.

One striking difference between T-type and L-type Ca channels in heart is seen when patches are excised (Fig. 2). As little as 1 min after manual excision of the patch from the cell-attached to the inside-out patch configuration, the activity of the L-type Ca channel (Fig. 2a) disappeared irreversibly (b), as previously reported $^{2}$, whereas $\mathrm{T}$-channel openings $(c)$ could still be recorded many minutes after the excision $(d)$, without a clear sign of decreasing activity. This contrast between the two channel types was seen consistently in each of five patches, with $T$. channel activity sometimes remaining up to the end of recordings as long as $20 \mathrm{~min}$.

Organic $\mathrm{Ca}$ channel antagonists are widely used in the management of cardiovascular disorders ${ }^{12}$ and in attempts at isolation and purification of $\mathrm{Ca}$ channels ${ }^{13}$, so it is important to look for differences in the responsiveness of the two types of $\mathrm{Ca}$ channel. We found that the dihydropyridine $\mathrm{Ca}$ channel antagonist nimodipine $(5 \mu \mathrm{M})$ halved the average current through the L-type $\mathrm{Ca}$ channel with $110 \mathrm{mM} \mathrm{Ba}$ as the charge in four patches with either $110 \mathrm{mM} \mathrm{Ca}$ or $\mathrm{Ba}$ as the charge carrier. The contrast between $\mathrm{Ca}$ channel types was also found for the dihydropyridine Ca agonist Bay K 8644 (ref. 14). Figure $3 a, b$ shows unitary currents from a patch that contained both channel types, with $110 \mathrm{mM} \mathrm{Ba}$ as the charge carrier. At a test potential of $-30 \mathrm{mV}$ in the absence of the drug (panel $a$ ), activity consists solely of T-type channel openings, as expected from the differing voltage sensitivity of the two channel types. After addition of $5 \mu \mathrm{M}$ Bay K 8644 (Fig. 3 b), depolarizations to the same test potential continue to evoke T-type channel activity, but with the additional appearance of unitary currents of large amplitude $(\sim 2 \mathrm{pA})$. The additional events are typical for Bay K 8644-promoted openings of L-type channels ${ }^{15-17}$, which are known to appear at negative test potentials where L-type channel activation is normally undetectable ${ }^{15}$. The lack of effect of Bay K 8644 on T-channel activity was documented by averaging only those sweeps which lacked large-amplitude unitary currents. The resulting mean current signal (next to last trace in Fig. $3 b$ ) closely matched the amplitude of the mean current before drug addition (Fig. $3 a$ ). When $\mathrm{Ca}$ was the charge carrier, the T-type channel was also insensitive to $5 \mu \mathrm{M}$ Bay K 8644 (not shown), whereas L-type channels clearly responded to the drug (Fig. $3 c$ d). The patch of Fig. $3 c$ contained only the L-type channel. At $+10 \mathrm{mV}$, its activity is apparent as very brief openings of $\sim 0.6 \mathrm{pA}$ amplitude. After addition of $5 \mu \mathrm{M}$ Bay $\mathrm{K} 8644$, many long-lasting openings are observed and the averaged current is increased $\sim 5$-fold (Fig. $3 d$ ). The open-time histogram after Bay K 8644 was composed of two exponential components corresponding to short-lived and long-lived open states, one with a very short time constant $(<0.3 \mathrm{~ms})$ as in the absence of drug, and an additional component with a time constant $\sim 10$ times as long. Thus, our experiments indicate that the contrast between Ca-agonist responsive and unresponsive activity arises from different channel types rather than different charge carriers: 


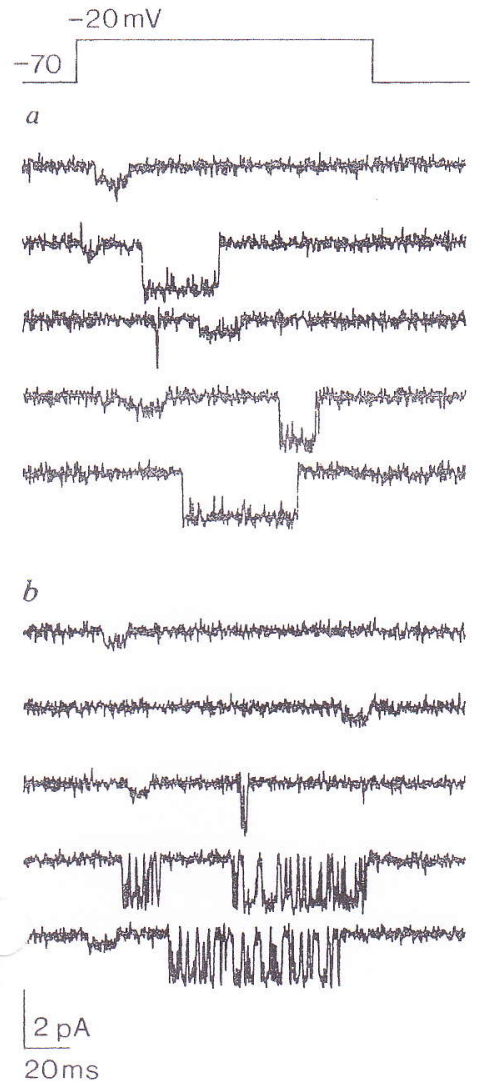

Fig. 4 Different effects of Cd on T-type Ca channels. Selected current traces from two cellattached patches. Pipettes contained $50 \mathrm{mM}$ Ba as the charge carrier with no $\mathrm{Cd}(a)$ or $10 \mu \mathrm{M} \mathrm{Cd}(b)$. Bath solution contained $5 \mu \mathrm{M}$ Bay K 8644. Upper trace shows the voltage clamp protocol. Cells G34C, G34K

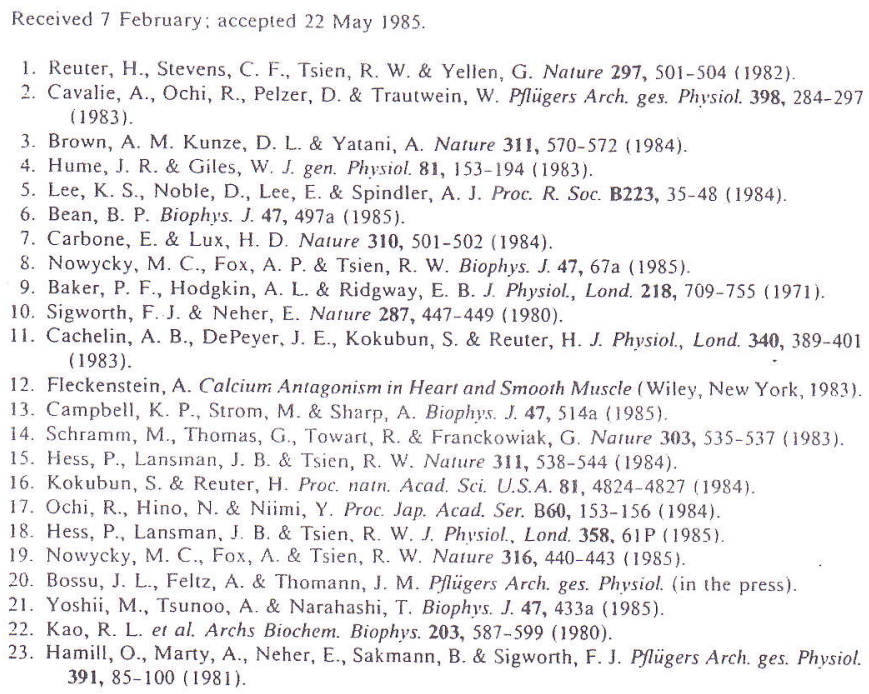

Sarcoplasmic reticulum contains adenine nucleotide-activated calcium channels

\author{
Jeffrey S. Smith*, Roberto Coronado $\dagger$ \\ \& Gerhard Meissner*
}

Departments of * Biochemistry and Nutrition and † Pharmacology, School of Medicine, University of North Carolina, Chapel Hill, North Carolina 27514, USA carrier (Fig. $3 a, b$ ) and L-type Ca channels are responsive even if Ca carries current (Fig. $3 c, d$ ).

The two types of $\mathrm{Ca}$ channels also showed different sensitivities to block by $\mathrm{Cd}$ ions (Fig. 4). The presence of micromolar $\mathrm{Cd}$ in the patch pipette inhibited L-type Ca channel activity; this was seen most clearly during the long-lasting openings promoted by Bay K 8644 as rapid flickering block ${ }^{18}$. In contrast to the clearcut response of L-type channels at $10 \mu \mathrm{M}$ $\mathrm{Cd}, \mathrm{T}$-type $\mathrm{Ca}$ channel openings were not detectably changed in their amplitude or duration. The difference in the Cd responsiveness of T-type and L-type Ca channels was observed in each of four patches containing both channel types. This information from single-channel recordings fits well with results from wholecell recordings in sensory neurones ${ }^{19,20}$, and neuroblastoma cells ${ }^{21}$.

We performed whole-cell recordings with $5 \mathrm{mM}$ external $\mathrm{Ca}$ or $\mathrm{Ba}$ and found an extra component of TTX-resistant inward current with properties corresponding to T-type Ca channels. Its peak amplitude was $5-10 \%$ of the peak L-type Ca channel current. Unlike maintained, TTX-resistant inward currents previously described in ventricular cells ${ }^{4,5}$, T-type current decays rapidly; it shows similarities, however, in its activation at negative potentials and its relative insensitivity to $\mathrm{Cd}$ ions ${ }^{5}$. Our results are consistent with the two components of $\mathrm{Ca}$ channel current described by Bean ${ }^{6}$ in atrial cells.

In out ventricular cells, T-channel current is much smaller and decays much more quickly than L-channel current, so it probably contributes relatively little to $\mathrm{Ca}$ influx during the action potential plateau and contraction. Like their counterparts in neurones 7,8 , cardiac T-type channels might have greatest significance for pacemaker depolarization and action potential initiation, electrical phenomena that depend critically on small inward currents at relatively negative potentials.

We thank M. C. Nowycky and A. P. Fox for helpful discussions, So Ching Wong for technical assistance, and the USPHS and Miles Pharmaceuticals for support. The work was
Rapid calcium effiux from the sarcoplasmic reticulum (SR) is a necessary step in excitation-contraction coupling in skeletal muscle and is thought to be mediated by a calcium channel ${ }^{1-3}$. Calcium efftux has been studied in fragmented SR vesicles by radioisotope efflux and fluorescence measurements. Several laboratories thave reported that adenine nucleotides can stimulate calcium efflux from $\mathrm{SR}^{4-7}$. In recent reports, $\mathrm{Ca}^{2+}$ release with a first-order rate constant as high as $100 \mathrm{~s}^{-1}$ has been observed for mucleotide-stimulated $\mathrm{Ca}^{2+}$ rellease from $\mathrm{SR}$ vesicles ${ }^{8,9}$. Also, radioisotope efflux was blocked by $\mathrm{Mg}^{2+}$ and micromolar concentrations of the polycationic dye, ruthenium red ${ }^{1-7}$. These high rates of transport are difficult to reconcile with a mechanism other than passive diffusion through a nucleotide-activated 'calcium release chamel ${ }^{7-9}$. Using the fusion technique for inserting $S R$ proteins into planar lipid bilayers ${ }^{10}$, we report here single-channel recordings of calcium release channels from purified 'heavy' SR membranes. Channels have been identified on the basis of their activation by adenine nucleotides, blockade by ruthenium red, and sellectivity for divalent cations. Surprisingly, the channel studied here exhibits an unusually large conductance of $170 \mathrm{pS}$ in $50 \mathrm{mM}$ $\mathrm{Ba}^{2+}$ while still being capable of discriminating against monovalent cations by a permeability ratio, $P(\mathrm{Ba}) / P(\mathrm{Cs})=11.4$.

In order to eliminate the contribution from SR monovalent cationic and anionic channels, which comprise the bulk of SR conductance 1.1 , and to provide a large divalent cation driving force across the bilayer, heavy SR vesicles were first fused into planar bilayers in asymmetric choline chloride, followed by perfusion with Tris/HEPES (cis side) and Ba/HEPES or $\mathrm{Ca} / \mathrm{HEPES}$ (trans ground side). (We chose the sidedness of the buffers based on the previous observations of Miller, which suggest that $S R$ vesicles insert into planar bilayers such that the cis chamber corresponds to the myoplasmic space, while the trans chamber is equivalent to the lumen of the $\mathrm{SR}^{12}$.) In our conditions, and according to our sign convention, the Nernst reversal potential $E_{\text {divalent }}=+125 \mathrm{mV}$ and $E_{\text {Tris }}$ is nominally minus infinite, and $E_{\text {HEPES }}=0 \mathrm{mV}$. Thus, divalent cation-selec- 